\title{
SUPPORTING COMPLETION OF AN ONLINE CONTINUING PROFESSIONAL DEVELOPMENT PROGRAMME FOR NEWLY QUALIFIED PRACTITIONERS: A QUALITATIVE EVALUATION
}

Rosie Erol, Penney Upton and Dominic Upton

\begin{abstract}
Background: Development programmes to support newly qualified practitioners gain confidence in their first professional role often show varied levels of engagement, due to competing priorities and demands. In Scotland, the Flying Start $\mathrm{NHS}^{\circledR}$ programme uses a structured programme of online and work-based learning with associated mentoring, to support individuals through an often difficult transition to become capable, confident practitioners. . Whilst the programme was generally well received, the factors leading to widely varying completion rates between professions and organisations were not well understood.
\end{abstract}

Aim: to identify the factors leading to successful completion of Flying Start, a transition programme for newly qualified practitioners.

Method: A qualitative approach was adopted to gather data from two groups of participants. Semistructured telephone interviews were conducted with strategic and management level participants $(n=23)$, from five health boards in Scotland. Semi-structured interviews $(n=22)$ and focus groups $(n=11)$ were conducted with practitioners within 6 months either side of completing the programme. The interviews were transcribed and analysed using framework analysis.

Results: Four key themes related to successful completion emerged from the analysis: organisational support; the format of the programme; understanding completion; motivation and incentives to complete. Factors leading to successful completion were identified at programme, organisational and individual level. These included clear communication and signposting, up-to-date and relevant content, links with continuing professional development frameworks, effective leadership, mentor and peer support, setting clear standards for assessment, and facilitating appropriate IT access.

Conclusions: A strong strategic commitment to embedding a development programme for newly qualified practitioners can ensure the necessary support is available to encourage timely completion. The mentor's role - to provide face-to-face support - is identified as a key factor in completion and is achieved through setting attainable targets, monitoring progress, and providing motivation. However organisational structures that facilitate the mentoring relationship are also necessary. 


\section{$\underline{\text { Key words }}$}

New graduate; transition programme; mentors; motivation; nurses; midwives; allied health professionals; online learning.

\section{INTRODUCTION}

A newly qualified practitioner's (NQP) first role, with its anticipated workload and responsibility, can seem daunting (Delaney 2003, Heap 2012); the challenges associated with the transition from being a student to a competent practitioner are reported (Higgins et al., 2010; Jewell, 2013; Whitehead et al., 2013), to include feelings of self-doubt, inadequacy, discouragement, exhaustion (Andersson and Edberg, 2010; Duchscher, 2009), uncertainty and anxiety (Brown and Edelmann, 2000; Delaney, 2003). Fitting into established teams and meeting the expectations of colleagues can add to the pressure of starting in this new role (Evans, 2001; Mooney, 2007).

Several initiatives have therefore been developed to ease this transition process, with a view to promoting safe and effective practice (Dyess and Sherman, 2009), improving retention (Jewell; 2013, Rush et al., 2013) and developing competency (Rush et al., 2013). The key factors associated with effective transition programmes include preceptorship or mentoring, and practical skill development (Clark and Holmes, 2007; Hughes and Fraser, 2011; Whitehead et al., 2013). Furthermore, formal support should be made available beyond initial induction and clinical orientation, and ideally throughout the first year of practice (Duchscher, 2008; Dyess and Sherman, 2009; Andersson and Edberg, 2010; Rush et al., 2013).

Delivering transition programmes for NQPs through online and blended learning methods is increasingly being adopted across the health professions. The benefits of developing web based support include the ability to access material as and when suits, therefore allowing NQPs to fit any studies around work and family commitments (Dawes and Handscomb 2002, Wilkinson et al., 2004). Furthermore, this approach allows the learner to study at their own pace, and can offer access to a wide range of material. However, research demonstrates that online training can create feelings of isolation, can leave the learner feeling overwhelmed by the volume of material available and is not suitable for all areas of work (Wilkinson et al., 2004, Chumley-Jones et al., 2002) which may impact on the completion rate of programmes compared to traditional methods.

According to Wilkinson et al. (2004), the factors contributing to a high (79\%) completion rate for online transition programmes include preparing NQPs with Information Technology (IT), independent 
learning, and time management skills, and ensuring mentors are sufficiently familiar with the elearning approach to help NQPs to navigate through the available material. Other factors include design effectiveness and quality of the learning material accessed online, web usability, in terms of navigating the site, and the usefulness and relevance of the course material (Atreja et al., 2008; Wong et al., 2010). Personal factors such as preferred learning style also influenced user experience satisfaction; demographics, practice setting and computer proficiency were less influential (Atreja et al., 2008, Sweeney et al., 2008), although the IT proficiency of participants should be taken into account when considering the design of the online resource (Wong et al., 2010).

Similar completion and achievement rates have been achieved for traditional and e-learning formats, when learners had clear guidance of what was expected from them at the outset, learning materials that were directly relevant to their experience, and effective tutor support (Probst et al., 2009). Having the same material available in various different formats (web-based, CD Rom, hard copy, classroombased) can help overcome the issues around adapting to individual learning preferences and the requirements of different clinical specialties (MacDuff et al., 2009).

\section{$\underline{\text { BACKGROUND }}$}

Flying Start NHS ${ }^{\circledR}$ is an online transition programme, introduced in 2006 to support all newly qualified nurses, midwives and allied health professionals (NMAHPs) entering employment with NHS Scotland during their first year of clinical practice. The programme, developed and administered by NHS Education for Scotland (NES), aimed to build confidence and competence, through structured online work packages, and an associated mentoring scheme, providing further development following preregistration education (Higgins et al., 2010). The content within the work units include communication, research for practice, clinical skills and policy, with each unit providing tasks and concluding activities to be completed. NQPs build up a portfolio of evidence to demonstrate that the Flying Start activities had been accomplished and the learning had been applied to practice during their first year of employment in line with the programme aims.

Early evaluations of the Flying Start $\mathrm{NHS}^{\circledR}$ programme and the Allied Health Professional Support and Development Scheme, showed that most newly qualified professionals found participation in the scheme to be a positive experience (Soloweij et al., 2010), particularly in relation to clinical skills development and confidence (Banks et al., 2011).

Banks et al. $(2010,2011)$ followed the first cohorts as they got to grips with the programme and identified issues as it was rolled out. Flying Start was seen to be most successful when the NQPs felt 
they had support from all levels of management and when there was a clear understanding of the purpose of the programme (Banks et al., 2011). However, it was also found that difficulties in completing the programme were experienced due to the technicalities of the system, and the need for further support. Furthermore, although the flexibility of the programme meant that there was no expectation that units would only be completed during on-duty-hours, competing pressures within work time were also identified as a barrier to programme completion. Lack of protected time for engaging with the programme was identified as a challenge by community based NQPs in particular. Differences in engagement and completion of the programme were also observed between clinical specialities and between different NHS Boards (Banks et al., 2011). It was therefore recognised that there were on-going issues with programme completion, and a so a separate independent evaluation was put in place to better understand the factors influencing completion rates as the programme evolved.

The aim of this study was therefore to identify the factors leading to successful engagement with, and completion of, the Flying Start $\mathrm{NHS}^{\circledast}$ programme from the perspective of newly qualified staff, managers and strategic leads, with a view to improving completion rates for the programme and achieving the learning aims within the prescribed time period.

\section{METHOD}

\section{$\underline{\text { Design }}$}

A qualitative approach was adopted to provide an in-depth understanding of the key characteristics of successful completion of Flying Start NHS. The research was designed to identify factors influencing programme completion by gathering the experiences of respondents from a wide range of occupational and geographical location, and with different expectations and levels of experience of the programme. In line with an inductive approach to research which aims to describe, decode and understand the meaning, not the frequency, of social phenomena, the project used a series of semistructured interviews and focus groups to collect data. The focus groups provided the opportunity to discuss certain topics highlighted in the interviews in more depth, and allow group interaction between participants. Participants were identified initially through purposive sampling, with the assistance of Flying Start leads within each NHS Board. Snowball sampling was then used to boost the number of Allied Health Profession (AHP) participants. It should be noted that whilst the Flying Start leads facilitated access to participants, all other aspects of the research from recruitment through to data collection and analysis was undertaken by an independent team from an English University. 


\section{Participants}

Two groups of participants were identified for interview, which took place during January and February 2012; those with a strategic or managerial role in the delivery of Flying Start (group 1), and those with experience of undertaking the programme (group 2) (table 1). Group 1 participants were recruited from five NHS Boards selected by NES, to be representative of a range of settings, including urban, remote and rural, and an Island Board. Research with group 2 participants focused on these five Boards and also included staff members from an additional five NHS Boards who responded to a

\begin{tabular}{|c|c|c|c|c|c|c|c|c|c|c|}
\hline & \multicolumn{6}{|c|}{ Group 1} & \multicolumn{4}{|c|}{ Group 2} \\
\hline & \multicolumn{2}{|c|}{$\begin{array}{c}\text { Executive } \\
\text { Nurse/AHP } \\
\text { Directors }\end{array}$} & \multicolumn{2}{|c|}{$\begin{array}{l}\text { Human Resources } \\
\text { and Learning \& } \\
\text { Development }\end{array}$} & \multicolumn{2}{|c|}{$\begin{array}{l}\text { Managers and } \\
\text { mentors }\end{array}$} & \multicolumn{2}{|c|}{$\begin{array}{l}\text { NQPs who had } \\
\text { completed the } \\
\text { programme }\end{array}$} & \multicolumn{2}{|c|}{$\begin{array}{l}\text { NQPs currently } \\
\text { enrolled on the } \\
\text { programme }\end{array}$} \\
\hline & $\mathrm{n}$ & $\%$ & $\mathrm{n}$ & $\%$ & $\mathrm{n}$ & $\%$ & $\mathrm{n}$ & $\%$ & $\mathrm{n}$ & $\%$ \\
\hline $\begin{array}{l}\text { Number of } \\
\text { participants }\end{array}$ & 5 & 21.7 & 7 & 30.4 & 11 & 47.8 & 20 & 60.6 & 13 & 39.4 \\
\hline male & 2 & 8.7 & 0 & 0.0 & 0 & 0.0 & 3 & 9.1 & 0 & 0.0 \\
\hline female & 3 & 13.0 & 7 & 30.4 & 11 & 47.8 & 17 & 51.5 & 13 & 39.4 \\
\hline AHP & $n / a$ & & $n / a$ & & 1 & & 6 & 18.2 & 7 & 21.2 \\
\hline Nurse & $n / a$ & & $\mathrm{n} / \mathrm{a}$ & & 8 & & 13 & 39.4 & 5 & 15.2 \\
\hline Midwife & $n / a$ & & $\mathrm{n} / \mathrm{a}$ & & 2 & & 1 & 3.0 & 1 & 3.0 \\
\hline $\begin{array}{l}\text { Mean time in } \\
\text { current role } \\
\text { (yrs) }\end{array}$ & $n / a$ & & $n / a$ & & 6.4 & & 2.3 & & 1.1 & \\
\hline
\end{tabular}

wider invitation to participate.

Table 1: Characteristics of participants, by Group

Of the NQPs who were currently enrolled and who had successfully completed that we talked to, the majority were based within an acute hospital setting, with 4 based wholly in a community setting (12\%), all of whom had successfully completed the programme. The AHPs came from various disciplines: Speech and Language therapy $(n=7)$, radiography $(n=2)$, occupational therapy $(n=2)$, physiotherapy $(n=1)$ and podiatry $(n=1)$.

Three focus groups were held in two NHS Boards; in one board separate focus groups were held with NQPs ( $n=3 ; 1$ nurse and 2 AHPs), and with those who had successfully completed ( $n=3$; all nurses) 
whilst in the other NHS Board this was with a mixed group of NQPs and those who had successfully completed ( $n=5 ; 4$ nurses and 1 midwife).

\section{Data Collection}

Participant information and consent forms were emailed to strategic and managerial participants and NQPs who had successfully completed the Flying Start Programme, explaining the nature and purpose of the study, the right to withdraw, issues of consent, and assuring confidentiality and anonymity. Telephone interviews were conducted once participants had provided informed consent; that is once they had had an opportunity to read and discuss the information provided to them about the study and had demonstrated that they understood and accepted their rights, the purpose and process of the study.

For the current users of Flying Start, all NQPs currently enrolled on Flying Start were emailed an invitation to participate in the study, which included information and consent forms as described above. Participants contacted the project team directly, and telephone interviews were conducted once informed consent had been given.

Interview schedules were adapted for each participant group, based around key themes designed to explore participants' experiences around Flying Start $\mathrm{NHS}^{\circledR}$, including expected outcomes of the programme; understanding of what constitutes 'successful completion'; organisational support; barriers and facilitators to engagement; and content and structure of the programme.

A similar approach was used to recruit participants for focus groups, in two NHS Boards, with potential participants based locally, and identified by local Flying Start coordinators, being sent information by the research team and invited to participate in the focus groups.

\section{$\underline{\text { Analysis }}$}

The interviews were transcribed, coded and analysed using the five key stages of framework analysis (Lacey and Luff 2007, Ritchie and Spencer, 1994). These stages are familiarisation with the data, and subsequent development of the framework. This is followed by indexing and charting of the data, linking data from participants to themes and emergent sub-themes, then interpretation, identifying patterns and key issues for the two participant groups. Data from the interviews and focus groups were analysed separately using the same framework approach, and then combined to draw out the key findings. These stages are outlined in Table 2. 
Table 2: Framework analysis process

\begin{tabular}{|c|c|c|}
\hline $\begin{array}{l}\text { Stage of } \\
\text { framework } \\
\text { analysis }\end{array}$ & \multicolumn{2}{|c|}{ Applying this to the data } \\
\hline Familiarisation & \multicolumn{2}{|c|}{ Transcription of the data and reading and re-reading transcripts } \\
\hline $\begin{array}{l}\text { Identifying a } \\
\text { thematic } \\
\text { framework }\end{array}$ & \multicolumn{2}{|c|}{$\begin{array}{l}\text { Initial identification of framework to incorporate the key themes and sub themes from } \\
\text { the research question (e.g. completion) and from familiarisation with the transcripts (e.g. } \\
\text { management, content). }\end{array}$} \\
\hline Indexing & \multicolumn{2}{|c|}{$\begin{array}{l}\text { Coding the data according to the themes, using a spreadsheet developed in Excel for this, } \\
\text { and adjusting sub themes as the process progressed. }\end{array}$} \\
\hline \multirow[t]{5}{*}{ Charting } & \multicolumn{2}{|c|}{ Creating charts summarising the data across the themes, cross referencing, for example: } \\
\hline & & $\begin{array}{l}\text { Key theme: participation and completion } \\
\text { Sub theme: Perceived success factors for completion }\end{array}$ \\
\hline & $\begin{array}{l}\text { current user } \\
\text { - nurse }\end{array}$ & $\begin{array}{l}\text { 1. being self motivated and proactive }(69-70,258) \\
\text { "Your own abilities and giving yourself time to get it done and reading and } \\
\text { reading to gain knowledge I think." (366-367) } \\
\text { 2. having a goal to no longer be an NQP }(222-226) \\
\text { 3. Personal benefits from having done the work }(282,270) \\
\text { 4. Having enough time - key factor in completion }(334-340) \text { having protected } \\
\text { time - compulsory study days for example. }(357) \\
\text { 5. strategic level support (352) }\end{array}$ \\
\hline & $\begin{array}{l}\text { Completer - } \\
\text { AHP }\end{array}$ & $\begin{array}{l}\text { 1. having time to complete the programme; juggling demands of job and FS } \\
\text { (247, 85-86) } \\
\text { 2. support from people who know about it -mentor, colleagues (257) }\end{array}$ \\
\hline & $\begin{array}{l}\text { current user } \\
\text { - midwife }\end{array}$ & $\begin{array}{l}\text { 1. progression to band } 6(130,194,208,232,245) \\
\text { 2. time management: "it's just basically time management and just being able } \\
\text { to dedicate so many hours a week to it, to do it" }(270-271)\end{array}$ \\
\hline $\begin{array}{l}\text { Mapping and } \\
\text { interpretation }\end{array}$ & \multicolumn{2}{|c|}{$\begin{array}{l}\text { Identifying patterns, associations and key issues from across the data set for the two } \\
\text { groups of participants and relating these back to the initial aims of the study. }\end{array}$} \\
\hline
\end{tabular}

\section{$\underline{\text { Ethics }}$}

NHS ethical approval was not required for this project as it was solely concerned with ascertaining the opinions of NHS staff in relation to their professional role (Department of Health, 2011). However, consent was sought from the Nurse or Allied Health Profession Director in each NHS Board to contact staff. 
Participants were informed of the purpose of the evaluation, given the opportunity to ask questions, and reassured that they would remain anonymous. Verbal consent was provided before each interview. Participants were given the opportunity to withdraw from the evaluation process at any time.

\section{$\underline{\text { RESULTS }}$}

A number of themes emerged from the data which were organised according to three key themes: Management and Delivery; Content and Material; Participation and Completion. These key themes and the sub-themes, organised according to participant group, are shown in Table 3.

Table 3 Themes developed from the framework analysis

\begin{tabular}{|c|c|c|}
\hline Major theme & Group 1 & Group 2 \\
\hline Management and Delivery & $\begin{array}{l}\text { - Initial and continued awareness } \\
\text { - Prioritising Flying Start } \mathrm{NHS}^{\circ} \\
\text { - Issues around workforce type } \\
\text { - Protected learning time } \\
\text { - Using a web-based programme }\end{array}$ & $\begin{array}{l}\text { - Initial awareness and expectations } \\
\text { - Support } \\
\text { - Monitoring and assessment } \\
\text { - Training and career progression } \\
\text { - Protected learning time } \\
\text { - Acknowledgement of completion } \\
\text { - Consistency of approach }\end{array}$ \\
\hline Content and Material & $\begin{array}{l}\text { - Relevance } \\
\text { - Perceived benefits of Flying Start } \\
\text { - Usefulness } \\
\text { - Links with career progression } \\
\text { - Reflective practice }\end{array}$ & $\begin{array}{l}\text { - Structure } \\
\text { - Relevance of content } \\
\text { - Experience of a web-based } \\
\text { programme }\end{array}$ \\
\hline Participation and completion & $\begin{array}{l}\text { - Understanding completion } \\
\text { - Perceived success factors } \\
\text { - Self-motivation } \\
\text { - Time }\end{array}$ & $\begin{array}{l}\text { - Understanding completion } \\
\text { - Perceived success factors } \\
\text { - Incentives to complete }\end{array}$ \\
\hline
\end{tabular}

\section{Management and Delivery}

Individual boards were responsible for interpreting and implementing national guidance on supporting Flying Start, which led to differences in the priority given to Flying Start. Concerns about low 
completion rates had been recognised in some areas, with action taken to increase the priority and support given to the programme. However, not all Boards had processes in place to monitor NQPs progress and completion of Flying Start modules; monitoring progress was particularly difficult where staff did not have substantive posts.

"it became more of a priority at an organisational level because we were identifying we had quite a number of practitioners who had commenced Flying Start and not completed." (Strategic - Nursing and Midwifery)

Some Boards made completion compulsory, prioritising this above all other training during the first year of employment. Where there was clear strategic support, and completion was expected, this was largely reflected by the extent to which the programme had been embedded throughout the organisation.

Whilst most managers and mentors understood the aims of Flying Start, there was less clarity about what their role as a manager or mentor entailed in relation to this. With it being a relatively new programme, few managers and mentors had direct experience of completing the programme themselves.

"A problem that we have here is that staff supporting [NQPs] actually didn't have a great understanding of Flying Start and what it was" (Manager - midwife)

Whilst many NQPs praised the support they had received (especially from their mentors and peers) they also described inconsistencies in the expectations of their mentors, with some imposing far more stringent assessment criteria than others, interpreting the guidelines differently. Ensuring the mentor and mentee agreed clear and shared expectations about the quantity and quality of work required helped to enable the NQP to progress.

"I've had two mentors to do mine... and they've both got totally different expectations of what you need to do" (NQP - nurse)

Concerns were also raised about the lack of consistency of assessment criteria across the programme, with NQPs citing perceived inconsistencies between their own experience and those of colleagues in other NHS Boards and professions.

Many NQPs discussed the challenges of managing their time and competing demands within the workplace. The provision of protected learning time and access to IT during work time varied, reflecting the priority given to the programme; whilst most staff had some protected learning time to 
complete the programme, this was insufficient, and almost all did additional work at home. Again, inconsistencies in protected learning time provision were seen between organisations, and also between different professions within the same organisation. Much depended on individual line manager support and team within which the NQP was based.

"We don't get protected time as such but the team would work round to give the new start the time to complete it, so that was it's more a team effort locally." (Manager - Midwife)

A number of respondents who had successfully completed the programme acknowledged that organisational improvements had been made recently to provide more effective support for those currently enrolled.

\section{Content and Material}

The majority of NQPs favoured the online learning approach, appreciating the flexibility to tailor the work to their own context. Whilst some staff preferred more traditional, classroom-based learning, it was recognised that the online approach was more appropriate, allowing flexible working around shift patterns and being able to resume work easily in different locations, such as on the ward, in the library or at home. There were frustrations with the technicalities of the site, such as hyperlinks not working, frequently being logged out after inactivity, and not linking directly to an electronic portfolio of work. This added to the time it took to complete the work.

"Its most useful because you can do it at home, most of my flying start I do at home, don't get time to do it at work." (NQP who completed the programme - nurse)

"A lot of the links didn't work, so it was very frustrating, so it was more time consuming." (NQP $-A H P)$

NQPs considered the relevance of the programme content to current practice and their ongoing continuing professional development within their clinical field to be important. However, there was a perception that the website provided hyperlinks to an overwhelming amount of material. Furthermore, many staff considered the content to be either too generic or too focused on nursing. It was suggested that better signposting of the information relevant to each profession would make navigation much easier. Although online guidance for working through the ten work packages is provided, few of the current users or staff who had successfully completed the programme were aware of this guidance. Thus rather than following the guidance provided, individuals adopted their own strategies for working through the programme, the most successful strategy of which appeared 
to be agreeing an appropriate approach with their mentor at an early stage. Both NQPs and managers indicated that having regular supervision and monitoring in place was a key factor in making progress.

"I had agreed with my mentor that I'd choose the bits from Flying Start, some modules that I could use to fill in the gaps from the NQP framework. So some of it l've just done concluding activities and other ones I've done some more activities in them." (NQP - AHP)

\section{Participation and Completion}

Completion of Flying Start occurred when all concluding activities for each work package had been finished, and mentors were satisfied that sufficient work had been carried out; however lack of consistent guidance resulted in uncertainty and variation in understanding 'completion'.

"One of the challenges that myself and my nursing colleague felt that it was a great programme but actually somebody could start on it and never know if they were finished." (Strategic-AHP)

On a more strategic level, completion was understood to be consolidating relevant practice-based skills and knowledge.

"For me the completion of Flying Start is when the individual determines that they have completed enough of the programme to consolidate their skills and knowledge in that first year of employment." (Strategic - AHP)

The programme was considered at strategic level and by NQPs to be the foundation for further longer term career and professional development, and completion of Flying Start was seen to mark the end of the transition period from an NQP to a fully-fledged, independent professional.

"To me it was kind of my transition period from going from a student to a qualified or a competent and confident staff nurse. So it was more another step in my career, feeling more confident with my own skills." (NQP - nurse)

Recognising the professional benefits of the programme, and links into career progression were the central motivating factor to maintain engagement with the programme over this year-long period of independent study. These often became more apparent towards the end of programme, after a period of reflection.

"I'll be quite honest when I first started the programme I didn't have a lot of faith that it was going to help me at all, but as I worked through it I actually found that it really enables you to sit down and reflect on how you are as a practitioner, how you communicate with people, where people fit into the team role." (NQP who completed the programme - nurse) 
Other motivating factors included enabling newly appointed staff to show commitment to their role and their employer, and providing evidence of development activity required by professional bodies.

"I wanted to demonstrate to people that were employing me that I had a positive attitude to the job and to career progression ... it gave me something concrete to show that I was committed." (NQP who completed the programme - nurse)

Financial incentives motivated some to complete, and this was particularly the case for the AHPs and midwives, for whom completion of the programme was linked to promotion to the next pay band.

"I think in order for me to get my increment I need to get my Flying Start so that's going to push me to get it." (NQP - AHP)

Having senior level acknowledgment of completion was appreciated by NQPs, with some Boards holding events to mark success on the programme. There was a clear perception from respondents at all levels that successful completion, regardless of organisational support, depended on selfmotivation, with the responsibility for completion resting with the NQP.

"...accepting their own responsibility and exercising the kind of self-determination about what they need to learn, where, how, when, and we should be encouraging that." (Strategic - AHP)

However, it was not always easy to find the self-motivation to continue to work on the programme after a day at work.

"I have got great intentions, I think I'll go home and do a bit, and when I get home I'm knackered and I can't do it." (NQP - nurse)

Drawing on the analysis from all respondents highlighted the key factors which influenced whether an NQP successfully completed the programme, across geographical and professional boundaries, and identified the level of influence for each factor to improve completion rates.

\section{DISCUSSION}

This paper explored how completion of an online programme for NQPs can be effectively supported and encouraged, through understanding the factors influencing completion, from the perspective of programme participants, their managers and mentors, and strategic leads. Strategic and manager level respondents highlighted individual level factors that they perceived as being the main drivers in promoting completion of Flying Start, including self-motivation on the part of the NQP, having a willingness to continue to learn (Lee, 2011), and recognising the longer-term benefits of professional 
development. Self-motivation, satisfaction with participation, recognition of the relevance and value of the programme, and the desire to progress are key factors for individuals maintaining interest throughout the training period (Deci and Ryan, 2000).

Organisational level factors for successful completion focused on having good mentor support to help NQPs achieve the learning outcomes (Chen and Jang, 2010), and having sufficient time to complete the programme; although some work at home was expected, NQPs often thought expectations were excessive (McVeigh, 2008; Banks et al., 2011). Where a greater strategic commitment to the programme was demonstrated through making completion mandatory, this was often reflected in the amount of protected learning time allocated to NQPs.

The importance of mentor support in the successful transition from student to confident and competent practitioner, their affect on the NQP learning experiences, their adaptability to the new workplace and team, and the start of professional development (Kaihlanen et al., 2013; Whitehead et al., 2013), was reiterated by this study. Stragetic leaders acknowledged the importance of NQPs having adequate support from directors, managers and mentors and colleagues within clinical team, and the need for staff to have sufficient information to be able to offer this support. Whilst mentors were willing to support NQPs, a lack of time (Hansen et al., 2011), information and training about how to do this most effectively sometimes hindered the process (Whitehead et al., 2015), reinforcing the findings of Banks et al. (2011). This may be addressed in the future through encouraging NQPs who have successfully completed the programme, and therefore have direct experience of the programme, to become future mentors. NQPs valued having effective mentor support throughout the programme, in setting appropriate targets to gauge progression, and in choosing an appropriate learning path for each individual, related to their current experience in practice, and providing an opportunity to reflect on this. The role of the mentor appears to be especially important in e-learning, to support knowledge and skills acquisition, and to ensure course satisfaction (Paechter et al., 2010). NQPs indicated that more informal peer support from colleagues and fellow NQPs also played an important part in completion, providing opportunities to discuss challenges as they arose.

Health boards which had strong leadership support for the programme and in which it was embedded throughout the organisation, made completion mandatory before further training was permitted. Mandatory completion would undoubtedly drive up completion rates; there is also evidence to suggest that making a course mandatory as opposed to voluntary appears to impact on how the information is received and used. Yassi et al. (2009) found that those were required to complete an online course adopted the information into their working practice more effectively than those 
undertaking the course voluntarily. Whilst this was partly to do with having dedicated training time, they also found that making a course mandatory increased the perception of management commitment to the course.

Programme level factors relating to successful completion included ensuring programme quality, adequate and consistent methods of monitoring completion, and maintaining consistency of expectations across professions and between organisations. Perceived or actual inequality between geographical areas and between professions was a repeated source of criticism by NQPs, therefore more consistency in the structure to support the programme is necessary to engender a sense of fairness, particularly between the professions.

Accessing online learning was seen to be a positive aspect of the programme, allowing individuals the flexibility to work at their own pace, and often reflecting previous experience of the blended learning approaches used during their university training (Pawlyn, 2012). More recent technical improvements, such as allowing the programme to be accessed on mobile devices have overcome some of the frustrations experienced by NQPs. Improved signposting and tailoring the content of the online programme, to ensure relevance to individuals and professions, may become increasingly important to maintain engagement. Sorgenfrei et al. (2013) suggest that e-learning may lead to more efficient time spent on training, making it easier for learners to focus on completing aspects of programme that are directly relevant to them and their work. However, this may lead to apparent lower completion rates if modules seen as irrelevant are disregarded, again emphasising the need for a common understanding of completion.

Future development of such programmes would need a strategic commitment to build in time and capacity to allow sufficient training of mentors, to ensure the aims and objectives of the programme are well understood by those supporting the NQPs during their first year, as well having clear assessment criteria. Further research into the effects on translation of the learning into practice of the widespread adoption of mobile technologies, and multiple platforms for accessing the programme, would be interesting.

The study has a number of limitations that need to be taken into account when considering these findings. The number of participants in each NHS Board was limited, so there was little scope to compare in detail the experiences of those in different professions, or between NHS Boards. Whilst using qualitative research is effective in gathering rich, in-depth information about a programme or initiative, it is not designed to be representative of the views from all NHS Boards, which would have different approaches to the delivery and management of the programme. 
Whilst there was a good response from those at a strategic and managerial level to the request to participate in the research process, recruiting NQPs to the study was more challenging, with around one third of those contacted agreeing to participate. Reasons for non-participation included not having time within their work schedule, and long term sick leave. However, interviews were continued until we believed we had reached saturation, when no new themes emerged from the interviews (Guest et al., 2006), so would expect to have identified the common experiences and perceptions from these interviewees.

\section{CONCLUSION}

Understanding the key characteristics that encourage the successful completion of any staff development programme is central to ensuring it remains effective in meeting its aims of developing the workforce. This paper adds to the existing literature on completion of online courses aimed at newly qualified healthcare professionals, as it not only considers the views of programme participants, but also those in a strategic and managerial role who support those enrolled on the programme on a day to day basis and also those with a strategic overview of the programme as a whole, and in a position to influence the organisational approach to NQP support. The programme needs to be seen to be relevant and of high quality to retain interest (Gazza \& Hunker, 2014). The role of the mentor to provide face-to-face support is identified throughout as a key factor in completion, through setting achievable targets, monitoring progress, and motivating the NQP, supported by an organisational structure to facilitate the mentor-NQP relationship.

\section{Acknowledgement}

This evaluation was funded by NHS Education for Scotland. Thanks go to Daniel Kay and Helena Darby for their contribution to the data collection.

\section{References}

Andersson, P., Edberg, A-K. (2010). The Transition From Rookie to Genuine Nurse: Narratives From Swedish Nurses 1 Year After Graduation. J Contin Educ Nurs, 41(4), 186-192.

Atreja, A., Mehta, N., Jain A., Harris, C., Ishwaran, H, Avital, M and Fishleder, M (2008) Satisfaction with web-based training in an integrated healthcare delivery network: do age, education, computer skills and attitudes matter? BMC Medical Education 2008, 8:48-56

Banks, P., Kane, H., Roxburgh, M., Lauder, W., Jones, M. , Kydd, A and Atkinson J. (2010) Evaluation of Flying Start NHS: final report. Report to NHS Education for Scotland.

Banks P., Roxburgh, M., Kane, H., Lauder, W., Jones, M. Kydd, A and Atkinson, J. (2011) Flying Start $\mathrm{NHS}^{\mathrm{Tm}}$ : easing the transition from student to registered health professional. Journal of Clinical Nursing 20, 3567-3576 
Brown, H., Edelmann, R., (2000). Project 2000: a study of expected and experienced stressors and support reported by students and qualified nurses. Journal of Advanced Nursing 31 (4), 857-864.

Chen, K-C, Jang S-J (2010) Motivation in online learning: Testing a model of self-determination theory. Computers in Human Behavior 26, 741-752

Chumley-Jones, H, Dobbie, A. and Alford, C (2002) Web-based Learning: Sound Educational Method or Hype? A Review of the Evaluation Literature Academic Medicine 77, S86 - S93

Clark, T., Holmes, S., 2007. Fit for practice? An exploration of the development of newly qualified nurses using focus groups. International Journal of Nursing Studies 44, 1210-1220.

Dawes, D., Handscomb, A., 2002. A pilot study to assess the case for e-learning in the NHS. NT Research 7 (6), 428-443.

Deci, E. L., \& Ryan, R. M. (2000). The "what" and "why" of goal pursuits: Human needs and the self determination of behavior. Psychological Inquiry, 11, 227-268.

Delaney C. (2003) Walking a fine line: graduate nurses' transition experiences during orientation. Journal of Nursing Education 42(10), 437-443.

Duchscher, J. B. (2008). A Process of Becoming: The Stages of New Nursing Graduate Professional Role Transition. The Journal of Continuing Education in Nursing, 39(10), 441-450.

Duchscher, J. B. (2009) Transition shock: the initial stage of role adaptation for newly graduated Registered Nurses. Journal of Advanced Nursing 65(5), 1103-1113.

Dyess, S. M., Sherman, R. O. (2009). The First Year of Practice: New Graduate Nurses' Transition and Learning Needs. The Journal of Continuing Education in Nursing, 40(9), 403-410.

Evans, K. (2001). "Expectations of newly qualified nurses", Nursing Standard, vol. 15, no. 41, pp. 33-38.

Gazza, E. A., \& Hunker, D. F. (2014). Facilitating student retention in online graduate nursing education programs: A review of the literature. Nurse Education Today, 34(7), 1125-1129.

Guest, G., Bunce, A., \& Johnson, L. (2006). How many interviews are enough? An experiment with data saturation and variability. Field methods, 18(1), 59-82.

Hansen, B. S., Gundersen, E. M., \& Bjørnå, G. B. (2011). Improving student supervision in a Norwegian intensive care unit: a qualitative study. Nursing \& Health Sciences, 13(3), 255-261. 
Heap, R. (2012) Transition to staff nurse can be a daunting but positive experience. Nursing Standard 26 (34), 28

Higgins,G., Spencer,R. and Kane,R. (2010) A systematic review of the experiences and perceptions of the newly qualified nurse in the United Kingdom Nurse Educ.Today, 2010, 30, 6, 499-508

Hughes, A.J. \& Fraser, D.M. (2011), "'SINK or SWIM': the experience of newly qualified midwives in England", Midwifery, 27 (3), 382-386.

Jewell, A., (2013) Supporting the novice nurse to fly: A literature review, Nurse Education in Practice, http://dx.doi.org/10.1016/j.nepr.2013.04.006

Kaihlanen, A. Lakanmaa, R and Salminen, L. (2013) The transition from nursing student to registered nurse: The mentor's possibilities to act as a supporter. Nurse Education in Practice vol 13, no 5, pp $418-422$

Lacey A. and Luff D. (2007) Qualitative Research Analysis. The NIHR RDS for the East Midlands/ Yorkshire \& the Humber.

Lee N-J (2011) An evaluation of CPD learning and impact upon positive practice change. Nurse Education Today 31, 390-395

MacDuff, C., Baguley, F., Gass, J., Tuckwell, M. and West, B. (2009) An evaluation of the impact of the NHS Education for Scotland Cleanliness Champions Programme on clinical practice. Aberdeen: Robert Gordon University

McVeigh, H. (2009) Factors influencing the utilisation of e-learning in post-registration nursing students. Nurse Education Today 29, 91-99

Mooney, M. (2007) Facing registration: the expectations and the unexpected. Nurse Education Today 27: $840-847$.

Paechter, M., Maier, B., \& Macher, D. (2010) Students' expectations of, and experiences in e-learning: Their relation to learning achievements and course satisfaction. Computers \& Education, 54(1), 222229.

Pawlyn, J. (2012). The use of e-learning in continuing professional development. Learning Disability Practice, 15 (1), 33-37. 
Probst, H., Eddy, D., Doughty,Jj. and Hodgson, D. (2009). Integrating e-learning into postgraduate radiotherapy and oncology education: a case study. E-Learning and digital media, 6 (4), 363-371.

Ritchie, J and Spencer, L (1994) 'Qualitative data analysis for applied policy research', in Bryman and Burgess, eds., Analysing Qualitative Data, London: Routledge, p173-194.

Rush K.L., Adamack M., Gordon J., Lilly M. and Janke R. (2013) Best practices of formal new graduate nurse transition programs: An integrative review International Journal of Nursing Studies 50 345-356

Soloweij, K., Upton, P. and Upton, D. (2010) Supporting the transition from student to practitioner: a scheme to support the development of newly qualified practitioners. Int J. Therapy and Rehab 17: 494-504

Sorgenfrei, C., Borschbach, A. and Smolnik, S. (2013) Understanding E-Learning Continuance Intention: Towards A Conceptual Model (2013). ECIS 2013 Completed Research. Paper 223.

Sweeney, N., Saarmann, L., Flagg, J., \& Seidman, R. (2008). The keys to successful online continuing education programs for nurses. Journal Of Continuing Education In Nursing, 39(1), 34-41.

Whitehead B, Owen P., Holmes, D., Beddingham, E., Simmons M., Henshaw L., Barton M. and Walker C. (2013) Supporting newly qualified nurses in the UK: A systematic literature review. Nurse Education Today 33 370-377

Whitehead, B., et al., (2015) Supporting newly qualified nurse transition: A case study in a UK hospital, Nurse Educ. Today http://dx.doi.org/10.1016/j.nedt.2015.07.008

Wilkinson, A., Forbes, A., Bloomfield, J. and Fincham Gee, C. (2004) An exploration of four web-based open and flexible learning modules in post-registration nurse education. Int. J. Nursing Studies 41: 411-424.

Wong, G., Greenhalgh, T. and Pawson, R. (2010) Internet-based medical education: a realist review of what works, for whom and in what circumstances BMC Medical Education 10:12

Yassi, A., Bryce, E. Maultsaid, D., Novak Lauscher, H. and Zhao, K (2009) The impact of requiring completion of an online infection control course on health professionals' intentions to comply with infection control guidelines: a comparative study Can J Infect Dis Med Microbiol 20:15-19 